\title{
Clinical Profile of Drooling in Cerebral Palsy Patients at Physical Medicine and Rehabilitation Department Dr. Soetomo General Hospital Surabaya Period January $1^{\text {st }}, 2016$ - December $31^{\text {st }}, 2017$
}

\author{
Baiq Dwi Hadiatul Azni ${ }^{1}$, Noor Idha Handajani ${ }^{\star}{ }^{*}$ I Gusti Made Reza Gunadi Ranuh ${ }^{3}$
}

${ }^{1}$ Faculty of Medicine, Universitas Airlangga, Surabaya, Indonesia.

2Department of Physical Medicine and Rehabilitation, Faculty of Medicine, Universitas Airlangga, Surabaya, Indonesia. ${ }^{3}$ Department of Physiology, Faculty of Medicine, Universitas Airlangga, Surabaya, Indonesia.

\section{A B S T R A C T}

Introduction: Cerebral palsy $(\mathrm{CP})$ is a non-progressive neurological motor disorder. The incidence of CP in developed countries is around 2 to 2.5/1,000 births. Drooling is a condition when the saliva comes out of the mouth uncontrollably. The number of drooling cases can be estimated to be $10-37 \%$ in children with CP. This study aimed to examine and analyze the clinical profile of drooling in CP patients who visited Physical Medicine and Rehabilitation Department Dr. Soetomo General Hospital Surabaya period January $1^{\text {st }}, 2016$ - December $31^{\text {st }}, 2017$ according to their ages, gender, CP types, swallowing disorders, speech disorders, and nutritional status.

Methods: This study used a retrospective analytical method, and used the patients' medical record data at Physical Medicine and Rehabilitation Department Dr. Soetomo General Hospital Surabaya period January 1st, 2016 - December $31^{\text {st }}$, 2017.

Results: There were 45 subjects consisted of 23 men and 22 women. The peak incidence occurred in the 1-5 years age range. Whereas the most type of CP were quadriplegic spastic. There were 7 patients (15.6\%) who suffered swallowing disorders, while speech disorders dominated the pattern of symptoms in the sample $(95.6 \%)$. A total of 21 people or $52.5 \%$ of patients with CP and having clinical manifestations of drooling had good nutritional status.

Conclusion: In this study, we can conclude that peak incidence of CP was mostly in the 1-5 years old range, and quadriplegic spastic was the most popular types of $\mathrm{CP}$. Speech disorders dominated the pattern of symptoms.

(C) 2020 JUXTA: Jurnal Ilmiah Mahasiswa Kedokteran Universitas Airlangga. Available at https://e-journal.unair.ac.id/juxta

* Correspondence: nooridha.handajani@yahoo.com

JUXTA: Jurnal Ilmiah Mahasiswa Kedokteran Universitas Airlangga

p-ISSN: 1907-3623; e-ISSN: 2684-9453

DOI: $10.20473 /$ juxta.V11122020.56-60

Open access under Creative Commons Attribution-ShareAlike 4.0 International License (CC-BY-SA)
ARTICLE INFO

Article history:

Received 8 June 2020

Received in revised form 3 July 2020

Accepted 6 July 2020

\section{Keywords:}

Cerebral palsy,

Drooling,

Swallowing disorder. 


\section{Introduction}

Drooling is a condition when saliva comes out of the mouth uncontrollably and continuously. This situation is part of normal physical growth in children aged less than 18 months old while drooling in children and adolescents is a condition caused by neurodegenerative diseases. 1,2 Drooling is classified into anterior and posterior drooling. The anterior type is the most common occurrence in children. Anterior drooling in excessive amounts can cause chapped skin, infections, dehydration, chewing disorders, and loss of self-confidence and social isolation. Whereas posterior drooling can cause shortness of breath, coughing, choking, vomiting, and penetration into the airways so that it can cause life-threatening pneumonia. ${ }^{1}$

Cerebral palsy (CP) was first introduced by William James Little in 1862, which is a neurological motor disorder that is not progressive. ${ }^{3}$ The incidence of CP in developed countries is around 2 to 2.5/1,000 births, and those with the highest risk are babies with premature birth. ${ }^{4}$ Although drooling is considered abnormal in children over 18 months old, it is estimated that $10-37 \%$ of children with $\mathrm{CP}$ experience drooling. ${ }^{1}$ Primary functions such as lip closure, suction pressure, and ingestion can be impaired due to delayed nerve development. In CP, the most likely pathophysiology associated with drooling cases is disruption of tongue mobility because salivary production is generally within normal limits. Hypersalivation can occur due to several conditions such as complex temporal lobe epilepsy, treatment or irritation factors such as teething, gastro-esophageal reflux, or it can also be a symptom of affective disorder. ${ }^{5}$

The high incidence of CP and the absence of accurate data regarding patients with drooling especially those who visited Physical Medicine and Rehabilitation Department Dr. Soetomo General Hospital Surabaya raised the desire of the author to find out about the distribution and analysis of drooling conditions in patients with $\mathrm{CP}$. The main problem why we needed to do a research on this topic was because drooling can cause serious complications. The lack of education or awareness about this condition can increase the incidence of complications. The author needed to know how much CP patients were drooling and about the patients' clinical profiles according to ages, gender, CP types, swallowing disorders, speech disorders, and their nutritional status. After collecting the data, we hoped it could be useful to increase awareness of common people especially medical personnel to prevent its complication and another condition that could be life threatening. In 2015, based on the data, the computer of medical record of Physical Medicine and Rehabilitation Department Dr. Soetomo General Hospital Surabaya recorded 110 visitors of $\mathrm{CP}$ patients. The following year the increase that occurred was not so significant, only 140 visits were recorded, but in 2017 it increased very dramatically reaching 1,074 visits (Data Recapitulation of Physical Medicine and Rehabilitation Department Dr. Soetomo General Hospital Surabaya). This research is expected to be useful as a reference for researches in the same field.

\section{Methods}

The population used in this study was CP patients in Physical Medicine and Rehabilitation Department Dr. Soetomo General Hospital Surabaya. Whereas the research subjects in this study were CP patients who were drooling in Physical Medicine and Rehabilitation Department Dr. Soetomo General Hospital Surabaya period January $1^{\text {st }}, 2016$ - December $31^{\text {st }}, 2017$. This study used a retrospective analytical method, and a total sampling of the patients' medical record data (secondary data). Another instruments used in this study were SPSS 22.0.0 for Windows, Microsoft Office 2007, and also Mendeley. The variables in this study were age, sex, type of $\mathrm{CP}$, swallowing disorders, speech disorders, and nutritional status in children with $\mathrm{CP}$ who were drooling. This research was conducted in October 2018 to January 2019 and used SPSS application to analyze the data. Ethical permits number for this study was 0554/KEPK/VIII/2018, issued on August 28 2018 by Ethical Committee of Dr. Soetomo General Hospital Surabaya.

\section{Results}

The total number of samples in this study were $45 \mathrm{CP}$ patients who were drooling at Physical Medicine and Rehabilitation Department Dr. Soetomo General Hospital Surabaya.

Table 1. Distribution data of research subjects.

\begin{tabular}{lcc}
\hline \multicolumn{1}{c}{ Categories } & $\mathbf{n}$ & $\%$ \\
\hline Gender & & \\
Male & 23 & 51.1 \\
Female & 22 & 48.9 \\
Age & & \\
$<1$ & 4 & 8.7 \\
$1-5$ & 36 & 78.3 \\
$5-8$ & 5 & 10.8 \\
$>8$ & 0 & 0 \\
CP type & & \\
CP Quadriplegic Spastic & 30 & 66.6 \\
CP Diplegic Spastic & 9 & 20 \\
CP Double Hemiplegic Spastic & 2 & 4.4 \\
CP Monoplegic Spastic & 1 & 2.2 \\
CP Hemiplegic Dextra & 1 & 2.2 \\
CP Triplegic Spastic & 1 & 2.2 \\
CP Unspecified & 1 & 2.2 \\
Swallowing disorder & & \\
Positive & 7 & 15.6 \\
Negative & 38 & 84.4 \\
Speech disorder & & \\
Positive & 43 & 95.6 \\
Negative & 2 & 4.4 \\
& &
\end{tabular}




\section{Nutritional Status based on Body \\ Weight/Age Index ( $<5$ th year)}

$\begin{array}{lcc}\text { Over } & 1 & 2.5 \\ \text { Good } & 21 & 52.5 \\ \text { Malnutrition } & 9 & 22.5 \\ \text { Poor } & 9 & 22.5\end{array}$

\section{Discussion}

From all CP patients who came to Physical Medicine and Rehabilitation Department Dr. Soetomo General Hospital Surabaya period January 1st, 2016 - December $31^{\text {st }}, 2017$ there were 45 cases that met the criteria, 4 cases with patients aged less than 1 years old (8.7\%), 36 cases with patients aged $1-5$ years old $(78.3 \%)$, and 5 cases with patients aged $6-8$ years old $(10.8 \%)$. This data is supported by a research from Bhopal Hospital in India. It showed the age distribution of CP sufferers with a vulnerable age of 6 months old - 1 year old as many as 3 cases (6\%), aged 1 5 years old as many as 34 cases (68\%), and aged $5-8$ years old as many as 13 cases (26\%). ${ }^{6}$ Whereas the data from Prof. Dr. RD Kandou General Hospital in Manado in 2016 found 33 cases of CP with age distribution of under 1 year old were 3 patients (9.1\%), 19 patients (57.6\%) aged $1-5$ years old, 9 patients (27.2\%) aged 5-8 years old, and 2 patients $(6.1 \%)$ aged over 8 years old. ${ }^{3}$ The results of the research conducted at a hospital in Turkey support the data obtained, namely the highest age distribution at age 1-5 years old with the number of 87 patients $(66.9 \%)$, while patients under 1 year old were only 6 people $(4.6 \%)$, and patients over 5 years old were 37 people $(28.5 \%) .{ }^{7}$ The studies illustrate that the incidence of CP is often diagnosed at the age of 1-5 years old, because at this time developmental delays and physical disorders will be more apparent thus parents become worried and immediately bring their children to health care facilities. In general, under the age of 1 year old, the symptoms are still not visible thus parents do not bring their children into health care facilities, and also can only be identified by very experienced doctors. ${ }^{6}$ A well-known phenomenon in the case of child neurology is an improvement of some severe symptoms in early life such as hypotony and hypertony, but these symptoms will disappear with age. This often happens to premature babies. These facts form the basis that the diagnosis of CP should not be done below the age of 24 months old unless the child has a very severe case or other supporting information (such as abnormalities in neuroimaging). ${ }^{8} \mathrm{CP}$ is a disease that can be obtained once in a lifetime and only during certain risk periods (early pregnancy until the age of 1 or 2 years old). Children aged 5 to 10 years old by definition do not have the possibility of having CP (head injuries that cause brain damage at this age cannot be diagnosed as $\mathrm{CP}$ ).

Distribution of CP patients according to gender, there were 23 cases or $51.1 \%$ followed by the number of female sufferers as many as 22 cases or $48.9 \%$. A research in Poland provides an overview of the gender distribution of a total 92 patients dominated by men with 64 cases or $69.6 \%$ and women in 28 cases or $30.4 \% .{ }^{9} \mathrm{~A}$ research from Bhopal Hospital, India found that CP patients were dominated by male, around 3.16:1 female. ${ }^{6}$ The results of a research in Turkey got similar data, about 79 cases of men or $60.8 \%$ and 51 cases of women or $39.2 \%$. Although a lot of data shows that male dominated the pattern of $\mathrm{CP}$, no definitive reason has been found for this difference. Experimental studies that have been conducted on adult animals and data from adult patients who have a history of stroke indicate that hormones such as estrogen will protect from hypoxic-ischemic injury, thus CP tends to occur in males. ${ }^{7}$ Other studies suggest that male in premature babies tends to suffer a white matter injury and intraventricular hemorrhage than female. Recent information states that there are differences in neurobiologists in men and women regarding the response to brain injury, thus it can produce differences in the growth of different neurons. ${ }^{3}$

The most common type of $\mathrm{CP}$ patients were quadriplegic spastic about 30 cases (66\%), diplegic spastic about 9 cases (20\%), double hemiplegic spastic about 2 cases (4.4\%), and 1 case for monoplegia spastic, hemiplegic dextra, triplegic spastic, and CP unspecified. Previous researchers found data that is almost similar to this research, in which they found the most common type were quadriplegic spastic about 45 cases (34.6\%) and diplegic spastic about 41 cases $(31.5 \%) .{ }^{7}$ Some special subtypes of CP have easy symptoms to notice than other subtypes. For example, a mild hemiplegic subtype with manifestation walking disorders/delays has the possibility of being undiagnosed because it has not exceeded the normal age of development. Quadriplegic spastic (choreoatetosis) subtype, on the other hand, has advantages because it has small possibility to be underdiagnosed. This fact contributes to higher classification on several subtypes. ${ }^{8}$

From all of CP patients who were drooling, there were 7 patients who had swallow disorders (15.6\%) and 38 others had no complaints in the swallowing process $(84.4 \%)$. This might occur because of the determination of symptoms based on the history of the patients' parents in the medical record data. Other studies have shown quite high results of swallowing disorders in CP patients because they have a standard instrumental evaluation of swallowing disorder which include : risk of aspiration (by observation and/or history), prior aspiration pneumonia, suspicion of pharyngeal/laryngeal problems like husky voice quality, and the existence of gurgly voice quality. Abnormalities in the process of swallowing can be detected by videofluoroscopic modified barium swallow (VMBS) because it provides dynamic visualization of oral, pharyngeal, and upper esophageal phases of swallowing. Moreover, we can use a specific key question to ask the patients' parents to assist in the determination of the need for comprehensive evaluation. The key is asking about feeding time if it takes more than 30 minutes and/or absence of weight gain for 2-3 months could be a sign of problem in children under 2 years old. ${ }^{10}$ In other studies, 
swallowing disorder occurred in $43 \%$ of all samples that was detected by VMBS. ${ }^{11}$ In Italy, the prevalence of swallowing disorder in children with neuromotor impairment is very high, about more than $90 \%$ of a cohort of 49 children with CP were diagnosed positively. ${ }^{12}$

We found that 43 cases or $95.6 \%$ of CP patients who met the criteria had speech disorders. This result was obtained using Denver Development Screening Test II. Itis a popular method of screening for child development disorders. The assessment is about motor, cognitive, and language domains. Unfortunately screening tests are not for diagnosing, it can be used only to classify children into categories such as "delayed", "at risk for delay", or "within normal limits" for age. ${ }^{13}$ This caused a not significant result with other studies. Speech disorder in CP is often associated with underlying motor disorders, dysarthria. In the United Kingdom, 35\% of CP patients have dysarthria. ${ }^{14}$ Another study showed that $50 \%$ of CP patients have dysarthria too. Therefore, it should use dysarthria to evaluate speech disorder, since it has a key perceptual characteristic to identify such as imprecise articulation, sound distortions, slow rate, and reduced intelligibility. ${ }^{15}$

Nutritional status according to WHO z score of 2006 , for children aged 0-5 years old can use $z$ score parameters of Body Weight/Age and Body Mass Index (BMI)/Age while for children over 5 years old absolutely use the $z$ parameter BMl/Age score. ${ }^{16} 40$ patients under 5 years old with Body Weight/Age parameters indicating good nutrition was in 21 cases $(46.7 \%)$, malnutrition in 9 cases $(20 \%)$, poor nutrition in 9 cases (20\%), and over nutrition in 1 case $(2.2 \%)$. The results of the research on nutritional status are following the theory that neurological lesions can affect the sensory and motor abilities of the oropharynx. Children with oral sensory problems will not accept oral stimulation, and usually the food may hold under the tongue. In contrast, children with oral motor problems are unable to manipulate food on the tongue. Therefore, the food may fall out of the mouth. Both of these problems affect nutritional status in children with CP by different process. ${ }^{10}$

The cause of malnutrition can be seen from several factors such as immediate causes, underlying causes, and the basic causes. The immediate cause is inadequate supply of food and severe infection or disease. A child's supply of foods and infection or disease is affected by underlying causes, including household food insecurity, inadequate childcare, unhealthy environment, and inadequate health service. The basic causes of malnutrition can lead to social and political economic crisis such as unemployment, inflation, lack of food availability, and poverty. ${ }^{17}$ The state of infection can be found in CP patients because the perinatal infection is one of the causes of $\mathrm{CP}$, thus it can be one of the causes of nutritional status below normal levels. ${ }^{18}$

\section{Conclusion}

In this study, we can conclude that peak incidence of $\mathrm{CP}$ was mostly in the 1-5 years old range, and quadriplegic spastic was the most popular types of CP. Speech disorders dominated the pattern of symptoms. The importance about this study is that we can find out the percentage of drooling in CP patients, thus health workers can pay more attention to this situation because it can cause serious complications. For further research, we recommend researchers to investigate risk factors and various types of complications from drooling.

\section{Acknowledgments}

The author thanks the parties involved in completing this study:

1. Dr. Sri Mardjiati Mei Wulan, dr., Sp. KFR (K) as one of the examiners who helped through criticism and gave advice as well as shared useful knowledge in the preparation of this study.

2. Field of Research and Development Dr. Soetomo General Hospital Surabaya and his staffs who helped and gave permission in this study.

3. Atika, S.Si., M.Kes as methodology and statistics supervisor.

4. Mrs. Rima as the medical record staff of Physical and Medicine Rehabilitation Department Dr. Soetomo General Hospital Surabaya who was very helpful to collect the patients' medical record data.

\section{CONFLICT OF INTEREST}

The author stated there is no conflict of interest in this study.

\section{REFERENCES}

1. Lesperance $M M$ and Flint PW. Cummings Pediatric Otolaryngology. 2015.

2. Silvestre-Donat FJ and Silvestre-Rangil J. Drooling. 2014; 24: 126-34.

3. Sitorus FSSAB, Mogi TI and Gessal J. Prevalensi Anak Cerebral Palsy di Instalasi Rehabilitasi Medik RSUP Prof.Dr.R.D.Kandou Manado Periode 2015. Jurnal Kedokteran Klinik. 2016: 14-9.

4. Gowda VK, Kumar A, Shivappa SK, et al. Clinical Profile, Predisposing Factors, and Associated Co-Morbidities of Children with Cerebral Palsy in South India. Journal of Pediatric Neurosciences. 2015; 10: 108-13.

5. Miranda-Rius J, Brunet-Llobet L, Lahor-Soler E and Farré M. Salivary Secretory Disorders, Inducing Drugs, and Clinical Management. International Journal of Medical Sciences. 2015; 12: 811-24.

6. Dr DSG, Dr Umesh P, Dr. Jyotsna S, Dr. Narmada P and Dr. Bhupendra Kumar R. Clinical, Neurodevelopmental and Etiological Profile of Children with Cerebral Palsy. Pediatric Review: International Journal of Pediatric Research. 2014; 1.

7. Fidan $\mathrm{F}$ and Baysal O. Epidemiologic Characteristics of Patients with Cerebral Palsy. Open Journal of Therapy and Rehabilitation. 2014; 02: 126-32.

8. Paneth N, Hong T and Korzeniewski S. The Descriptive Epidemiology of Cerebral Palsy. Clinics in Perinatology. 2006; 33: 251-67.

9. Kułak P, Maciorkowska E and Gościk E. Selected Risk Factors for Spastic Cerebral Palsy in a Retrospective Hospital-Based Case Control Study. Progress in Health sciences. 2014; 4: 7-13. 
10. Arvedson JC. Feeding Children with Cerebral Palsy and Swallowing Difficulties. European Journal of Clinical Nutrition. 2013; 67: S9-S12.

11. Erasmus CE, van Hulst K, Rotteveel JJ, Willemsen MA and Jongerius PH. Clinical Practice: Swallowing Problems in Cerebral Palsy. European Journal of Pediatrics. 2012; 171: 409-14.

12. Salghetti $A$ and Martinuzzi A. Dysphagia in Cerebral Palsy. Eastern Journal of Medicine. 2012; 17: 188-93.

13. Fernald LC, Prado E, Kariger $P$ and Raikes A. A Toolkit for Measuring Early Childhood Development in Low and Middle-Income Countries. 2017.

14. Watson RM and Pennington L. Assessment and Management of the Communication Difficulties of Children with Cerebral Palsy: A UK Survey of SLT Practice. International Journal of Language \& Communication Disorders. 2015; 50: 241-59.
15. Allison KM and Hustad KC. Acoustic Predictors of Pediatric Dysarthria in Cerebral Palsy. Journal of Speech, Language, and Hearing Research : JSLHR. 2018; 61: 46278.

16. Indonesia KKR. Standar Antropometri Penilaian Gizi Anak. In: Indonesia KMKR, (ed.). Jakarta: Kementerian Kesehatan Republik Indonesia, 2010.

17. Fund UNCs. UNICEF's Approach to Scaling Up Nutrition for Mothers and Their Children. In: Division P, (ed.). New York: UNICEF, 2015.

18. Marret S, Vanhulle $\mathrm{C}$ and Laquerriere $\mathrm{A}$. Pathophysiology of Cerebral Palsy. Handbook of Clinical Neuroloy. 2013; 111: 169-76. 